\title{
Outbreak of gastroenteritis caused by norovirus GII.4 Sydney variant after a wedding reception at a resort/activity centre, Finland, August 2012
}

\author{
A. POLKOWSKA ${ }^{1,2 *}$, M. RÖNNQVIST ${ }^{3}$, O. LEPISTÖ $^{4}$, M. ROIVAINEN $^{1}$, \\ L. MAUNULA ${ }^{3}$, S. HUUSKO ${ }^{1}$, S. TOIKKANEN ${ }^{1}$ AND R. RIMHANEN-FINNE ${ }^{1}$ \\ ${ }^{1}$ National Institute for Health and Welfare (THL), Department of Infectious Disease Surveillance and Control, \\ Helsinki, Finland \\ ${ }^{2}$ European Programme for Intervention Epidemiology Training (EPIET), Stockholm, Sweden \\ ${ }^{3}$ Department of Food Hygiene and Environmental Health, Faculty of Veterinary Medicine, University of \\ Helsinki, Helsinki, Finland \\ ${ }^{4}$ Environmental Health Care Unit Pirteva, Pirkkala, Finland
}

Received 29 May 2013; Final revision 11 September 2013; Accepted 16 October 2011; first published online 13 November 2013

\section{SUMMARY}

In August 2012, an outbreak of gastroenteritis occurred among 88 persons attending a wedding reception at a resort/activity centre in Ylöjärvi, Finland. Of 39 interviewed guests, 23 met the case definition. Two persons were hospitalized. Epidemiological, laboratory and environmental investigations were conducted to characterize the outbreak and to recommend control measures. Investigation confirmed the presence of a new strain of norovirus GII.4 Sydney variant in stool specimens obtained from two wedding guests and on several environmental surfaces in the centre. In the questionnaire study, none of the foods or beverages served during the reception were significantly associated with the illness. Additional cases of gastroenteritis that occurred at the centre before and after the wedding reception supported the hypothesis of environmental transmission of norovirus. After thorough cleansing and disinfection and 1 week's quarantine, no new cases with symptoms typical for norovirus infection were identified at the centre.

Key words: Epidemics, gastroenteritis, Norwalk agent and related viruses.

\section{INTRODUCTION}

Infections with norovirus (NoV) are one of the leading cause of viral gastroenteritis worldwide [1-4]. Typically, infection with $\mathrm{NoV}$ is self-limiting and is characterized by nausea, vomiting, abdominal pain and diarrhoea. The incubation period ranges from 24 to $48 \mathrm{~h}$ [5]. The most important routes of transmission are faecal-oral, vomit-oral and from person to person. The main vehicle of infection is contaminated food or water. The virus is highly

\footnotetext{
* Author for correspondence: Miss A. Polkowska, Mannerheimintie 166, 00271 Helsinki, Finland.

(Email: aleksandra.polkowska@thl.fi)
}

contagious, an estimated dose $\geqslant 18$ viral particles is sufficient to cause infection [6]. Noroviruses are environmentally stable. They can survive freezing, heating $\left(30 \mathrm{~min}\right.$ at $\left.60^{\circ} \mathrm{C}\right)$ and are resistant to relatively high concentrations of chlorine [1, 7]. Several outbreaks with widespread contamination of environments have been reported, particularly in closed settings [8-10].

In Finland, the municipal authorities report suspected foodborne and waterborne outbreaks to the national online registry (FWD registry) developed and maintained by the National Institute for Health and Welfare (THL) and the Finnish Food Safety Authority Evira. In 1995, Finland initiated 
nationwide laboratory-based surveillance for NoV infections. Between 1998 and 2011, the annual number of cases of NoV infection reported to the National Infectious Diseases Register ranged from 125 to 2807. Since 1997, NoV has been the most common cause for foodborne and waterborne outbreaks [11]. During 1998-2002, the most common NoV genogroup causing gastroenteritis outbreaks was genogroup II accounting for $219(87 \%)$ of 252 outbreaks, genogroup I caused $33(13 \%)$ outbreaks [12].

On 20 August 2012, an infectious disease nurse from the Epidemiology Unit at the Helsinki City Health Department informed Pirkkala Environmental Health about gastroenteritis in two guests at a wedding buffet that was held on 18 August 2012. The wedding reception took place at a resort/activity centre (hereafter referred to as the centre) in Ylöjärvi, Finland. On 20 August, the municipal authorities were notified of the outbreak through the FWD registry. We investigated the outbreak in order to identify the source and aetiology of the infections, undertake control measures and prevent similar outbreaks in the future.

\section{METHODS}

\section{Description of the location}

The centre is located on Lake Näsijärvi, in the municipality of Ylöjärvi, in western Finland. The centre consists of a main building with an event hall, kitchen, sauna, 10 guest rooms with toilets, and three cottages.

\section{Epidemiological investigation}

NoV was suspected as the cause of the outbreak since the incubation period, and the description and duration of symptoms of the three guests with gastroenteritis were consistent with $\mathrm{NoV}$ infection. We defined a case as a person who attended the wedding buffet on 18 August 2012 at the centre and developed at least one of the following symptoms between 18 and 21 August 2012: diarrhoea ( $\geqslant 3$ loose stools a day), vomiting, nausea or abdominal pain.

Health inspectors obtained email addresses of 54 wedding guests and on 30 August, we sent them a web link to a standardized online questionnaire. The self-administered questionnaire gathered information on demographic details, food and beverages consumed during the reception, date and time of onset, duration and characteristic of clinical symptoms, collection of stool specimens and hospitalization.
We performed a descriptive analysis of cases. We compared the exposed with the unexposed through the calculation of attack rates, with $95 \%$ confidence intervals also calculated. All statistical analyses were conducted using Stata v. 12 (StataCorp., USA).

\section{Environmental investigation}

On 21 August, the municipal health inspectors contacted the wedding organizers, visited the centre, and investigated the general hygiene of the kitchen. The employees of the centre were asked to provide faecal specimens for bacterial and viral analysis and they were supplied with sampling containers. Food samples were not collected since they were no longer available.

\section{Laboratory investigation}

Stool specimens were provided by three guests of the wedding buffet with gastrointestinal symptoms. The specimens were tested for Salmonella, Shigella, Campylobacter, Yersinia spp., S. aureus, B. cereus, $C$. perfringens by routine methods [13] and for $\mathrm{NoV}$ using real-time reverse transcription (RT)-PCR assay in a local clinical microbiology laboratory and a virology laboratory, respectively. The specimens of the staff were not tested since the laboratory did not receive a referral.

Water specimens were obtained from the tap in the kitchen, from the lake (on 22 August), and from the ice cube machine (on 4 September). Specimens were tested for gut-derived enterococci, E. coli and coliform bacteria.

On 21 August, the municipal health inspectors collected environmental specimens from the baking board, cutting board and cold pantry handle, to test for aerobic bacteria and Salmonella.

In total, 36 swabs from surfaces at the premises in the centre were taken for $\mathrm{NoV}$ analysis. On 22 August, the municipal health inspectors obtained 27 surface specimens for NoV analysis from the main building in the centre. Surfaces were brushed with swabs, which were inserted into a tube containing $5 \mathrm{ml}$ phosphate buffered saline (PBS). The swabs were subjected to nucleic acid extraction using NucliSENS ${ }^{\mathbb{R}}$ miniMAG ${ }^{\circledR}$ kit (bioMérieux, The Netherlands) while viral RNA from polymerase-capsid gene junction was amplified using primers and probes specific for NoV genogroups I and II, and QuantiTect probe RT-PCR kit (Qiagen, Germany) in real-time 
RT-PCR according to the methods previously described $[14,15]$. On 28 August, after the first cleansing, five specimens were taken from places where noroviruses were detected previously. The final collection of four environmental specimens was performed after the second cleansing, on 4 September.

Genotyping analysis was done for three NoV isolates from swabs and from two NoV isolates from patients' stools. Viral RNA was amplified in polymerase region A using a one-step RT-PCR kit (Qiagen) according to Vinjé et al. [16]. Nucleic acid sequences of the PCR products were determined. A genotyping tool (www.rivm.nl) and BLAST search in Genbank were used for genotype determination. In addition, one NoV isolate from a swab specimen was amplified in region $\mathrm{D}$ and used for genotype determination [16].

\section{RESULTS}

\section{Epidemiological investigation}

Eighty-eight guests from various countries attended the wedding buffet, of which $54(61 \%)$ had an email address. Thirty-nine $(72 \%)$ responded to the survey $(59 \%$ female). The median age of respondents was 37 years (range 27-68 years). Twelve respondents were from abroad (France, $n=6$; Italy, $n=4$; Switzerland, $n=2$ ). Seven guests had travelled abroad (to France, Italy, Germany, Denmark, Sweden) in the 2 weeks before the wedding reception. Twenty-three $(59 \%)$ of respondents met the case definition. The highest attack rate $(71 \%)$ was in the $20-30$ years age group. The attack rate was $65 \%$ in females and $50 \%$ in males (Table 1).

All 23 cases became ill within a 3-day period, 19-21 August 2012 (Fig. 1). The symptoms of the first case started $12 \mathrm{~h}$ after the reception ended. The peak of the outbreak was on 20 August, when $15(65 \%)$ cases fell ill, and the outbreak ended on 21 August.

The most commonly reported symptoms were nausea $(91 \%)$, abdominal pain $(74 \%)$, diarrhoea $(70 \%)$, vomiting $(48 \%)$, headache $(39 \%)$, and fever $(13 \%)$. Two cases $(9 \%)$ were hospitalized.

None of the foods or beverages served at the wedding reception was significantly associated with the illness (Table 2).

\section{Environmental investigation}

In the kitchen, the general hygiene was according to requirements. During the visit to the centre on
Table 1. Attack rate (AR) of gastrointestinal symptoms by age group and gender, wedding reception, Ylöjärvi, Finland, August 2012

\begin{tabular}{lccc}
\hline \hline $\begin{array}{l}\text { Demographic } \\
\text { characteristics }\end{array}$ & $\begin{array}{l}\text { No. of } \\
\text { persons }\end{array}$ & No. ill & AR (\%) \\
\hline Age group (yr)* & & & \\
$20-30$ & 7 & 5 & 71 \\
$31-40$ & 19 & 11 & 58 \\
$41-50$ & 0 & - & - \\
$51-60$ & 4 & 2 & 50 \\
$>60$ & 8 & 5 & 62 \\
Gender & 16 & 8 & 50 \\
Male & 23 & 15 & 65 \\
Female & 39 & 23 & 60 \\
Total & & \\
\hline \hline
\end{tabular}

* One person did not report their age.

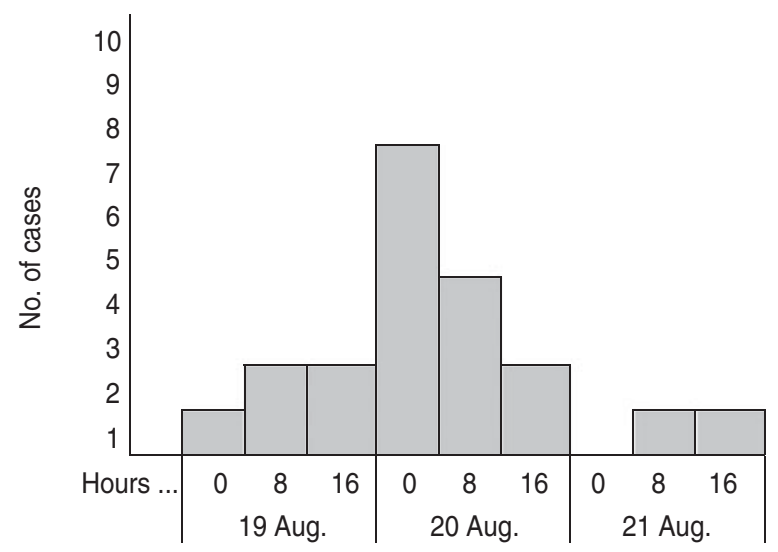

Fig. 1. Distribution of cases with acute gastroenteritis $(n=20)$ in guests at the wedding reception according to date and time of symptoms onset (three persons did not indicate the time of symptoms onset), Ylöjärvi, Finland, August 2012.

21 August and during the phone interview with the manager of the centre on 22 August, the health inspector identified three staff members (two customer service staff and a cleaner) who were ill with symptoms consistent with NoV infection. All had become ill on 21 August, following the wedding, and had not been symptomatic at work. The investigation also indicated that the day before the wedding buffet (17 August 2012), nine people who were staying at the centre, and had received food service, had subsequently developed gastrointestinal illness with symptoms typical for NoV infection after leaving the centre. None of these were accommodated in the same rooms as the wedding guests. Three days after the wedding, the next group of 20 people attended and ate at centre. 
Table 2. Attack rates and relative risk of acute gastroenteritis associated with specific food items and beverages consumed during a wedding reception, Ylöjärvi, Finland, August 2012

\begin{tabular}{|c|c|c|c|c|c|}
\hline & $\begin{array}{l}\text { Attack rate } \\
\text { in exposed }\end{array}$ & $\begin{array}{l}\text { Attack rate } \\
\text { in non-exposed }\end{array}$ & $\mathrm{RR}$ & $95 \% \mathrm{CI}$ & $\begin{array}{l}\text { Cases } \\
\text { exposed, \% }\end{array}$ \\
\hline \multicolumn{6}{|l|}{ Food items } \\
\hline Salmon with basil & $59(22 / 37)$ & $0(0 / 0)$ & - & - & 96 \\
\hline Shrimp salad & $63(17 / 27)$ & $33(2 / 6)$ & $1 \cdot 9$ & $0 \cdot 59-6 \cdot 07$ & 74 \\
\hline Baltic herring rolls & $70(14 / 20)$ & $42(5 / 12)$ & $1 \cdot 7$ & $0 \cdot 81-3 \cdot 48$ & 61 \\
\hline Olive rosemary focaccia & $75(12 / 16)$ & $55(6 / 11)$ & $1 \cdot 4$ & $0 \cdot 75-2 \cdot 53$ & 52 \\
\hline Country salad with chicken meat & $65(15 / 23)$ & $50(4 / 8)$ & $1 \cdot 3$ & $0 \cdot 61-2 \cdot 77$ & 65 \\
\hline Castle roast beef & $62(15 / 24)$ & $50(6 / 12)$ & $1 \cdot 2$ & $0 \cdot 66-2 \cdot 38$ & 65 \\
\hline Garlic potatoes & $61(19 / 31)$ & $50(2 / 4)$ & $1 \cdot 2$ & $0 \cdot 44-3 \cdot 40$ & 83 \\
\hline Watermelon feta salad & $63(17 / 27)$ & $57(4 / 7)$ & $1 \cdot 1$ & $0 \cdot 55-2 \cdot 23$ & 74 \\
\hline Rye buttons & $67(6 / 9)$ & $62(10 / 16)$ & $1 \cdot 1$ & $0 \cdot 59-1 \cdot 94$ & 26 \\
\hline Olive oil and white balsamic vinegar & $64(7 / 11)$ & $61(8 / 13)$ & $1 \cdot 0$ & $0 \cdot 56-1 \cdot 92$ & 30 \\
\hline Sugar frosting & $61(20 / 33)$ & $60(3 / 5)$ & $1 \cdot 0$ & $0 \cdot 47-2 \cdot 17$ & 87 \\
\hline Vanilla cream puffs & $67(14 / 21)$ & $67(8 / 12)$ & $1 \cdot 0$ & $0 \cdot 61-1 \cdot 65$ & 61 \\
\hline Sour cream herb sauce & $60(9 / 15)$ & $70(7 / 10)$ & $0 \cdot 9$ & $0 \cdot 48-1 \cdot 53$ & 39 \\
\hline Baked root vegetables & $68(19 / 28)$ & $100(1 / 1)$ & $0 \cdot 7$ & $0 \cdot 53-0 \cdot 88$ & 83 \\
\hline \multicolumn{6}{|l|}{ Beverages } \\
\hline Water & $63(22 / 35)$ & $0(0 / 1)$ & - & - & 96 \\
\hline Tea & $100(5 / 5)$ & $57(16 / 28)$ & $1 \cdot 7$ & $1 \cdot 27-2 \cdot 41$ & 22 \\
\hline Juice & $62(10 / 16)$ & $59(13 / 22)$ & $1 \cdot 1$ & $0 \cdot 63-1 \cdot 77$ & 43 \\
\hline Mineral water & $60(12 / 20)$ & $61(8 / 13)$ & $1 \cdot 0$ & $0 \cdot 56-1 \cdot 71$ & 52 \\
\hline Coffee & $58(18 / 31)$ & $71(5 / 7)$ & $0 \cdot 8$ & $0 \cdot 47-1 \cdot 42$ & 78 \\
\hline Homemade rye beer & $33(2 / 6)$ & $64(16 / 25)$ & $0 \cdot 5$ & $0 \cdot 16-1 \cdot 68$ & 9 \\
\hline Milk & $0(0 / 1)$ & $64(21 / 33)$ & $0 \cdot 0$ & - & 0 \\
\hline
\end{tabular}

RR, Risk ratio; CI, Confidence interval.

Within $36 \mathrm{~h}$ of their arrival, five persons had fallen ill with gastrointestinal symptoms.

\section{Laboratory investigation}

Two stool specimens from the wedding guests were positive for NoV. Salmonella, Shigella, Campylobacter, Yersinia spp., S. aureus, B. cereus, C. perfringens were not found in any of the specimens tested.

Water specimens from the lake and the tap in the kitchen were negative for gut-derived enterococci, $E$. coli and coliform bacteria $(0 \mathrm{MPN} / 100 \mathrm{ml})$. The level of heterotrophic spore-forming bacteria [240 colony-forming units (c.f.u.)/ml] in the ice-cube specimen was over the recommended limit (100 c.f.u./ml) of the Finnish Food Safety Authority Evira.

The microbiological quality of the surface hygiene and water specimens collected on 21 and 22 August was satisfactory. The level of aerobic microorganisms was: 76 c.f.u. $/ \mathrm{cm}^{2}$ for the baking board, 3 c.f.u. $/ \mathrm{cm}^{2}$ for the cutting board, and 80 c.f.u. $/ \mathrm{cm}^{2}$ for the cold pantry door handle. All specimens were negative for Salmonella.
Out of 27 environmental specimens collected on 22 August, nine were positive for NoV. NoV was detected in the kitchen, two hotel rooms and in the main building of the centre (Table 3). The results of five specimens obtained on 28 August taken after cleansing of previously contaminated surfaces, confirmed the presence of $\mathrm{NoV}$ in one room. On 4 September, after further cleansing, NoV was no longer detected.

$\mathrm{NoV}$ isolates from two patients and from three swab specimens taken from the surfaces of one guest room were characterized further by sequence analysis. All sequences were identical and were characterized as NoV genotype GII.4. The virus strain was $98.9 \%$ and $98 \cdot 5 \%$ identical with GII.4 Sydney variant (accession no. JX459908) in polymerase region A and capsid region $\mathrm{D}$, respectively.

\section{DISCUSSION}

The results of this investigation indicated that the outbreak of NoV gastroenteritis occurred in persons who attended a wedding reception at the centre. NoV was 
Table 3. Environmental specimens tested for norovirus at the centre, Ylöjärvi, Finland, 2012

\begin{tabular}{llll}
\hline \hline & & $\begin{array}{l}\text { No. of specimens positive } \\
\text { for norovirus/no. of } \\
\text { Specimens taken }\end{array}$ & $\begin{array}{l}\text { Surfaces with } \\
\text { positive results }\end{array}$ \\
\hline 22 Aug. 2012 & Kitchen & $2 / 5$ & $\begin{array}{l}\text { Freezer door handle } \\
\text { Tap handle } \\
\end{array}$ \\
& Room A & $4 / 4$ & $\begin{array}{l}\text { Surface with vomit } \\
\text { Mattress } \\
\end{array}$ \\
& & & Tap handle \\
& Room B & $2 / 3$ & Toilet seat \\
& & & Soap devices \\
& Storehouse & $0 / 2$ & Pooled specimen \\
& Meeting hall & $0 / 7$ & - \\
& Sauna & $0 / 3$ & - \\
28 Aug. 2012 & Kain building & $1 / 3$ & Door handles \\
(after first & Room A & $1 / 1$ & - \\
cleaning) & Room B & $0 / 1$ & Pooled specimen \\
& Main building & $0 / 1$ & - \\
4 Sept. 2012 & Room A & $0 / 4$ & - \\
(after second & & & - \\
cleaning) & & & \\
\hline \hline
\end{tabular}

detected in two stool specimens obtained from wedding guests and in 10/36 environmental specimens collected from the centre. The high attack rate and clinical picture reported by the cases are typical for NoV infection. The distribution of cases with a rapid increase and decline and a single peak suggest a point-source outbreak. The statistical analysis of data on food and beverage consumption by the guests did not indicate any specific source of infection. The high attack rate $(100 \%)$ and risk ratio $(1 \cdot 75)$ for drinking tea was not considered relevant, since only five cases had been drinking tea at the buffet.

The general hygiene of the centre's kitchen was visually good and none of the kitchen staff had been symptomatic at work. However, NoV was detected on the freezer handle and the kitchen tap handle, indicating that contaminated hands had been touching them. No stool samples from the staff were tested for NoV and none of the food that had been served was available for analysis. In order to assess the microbiological causality, samples from staff members and food served should be available for testing, and the laboratories should be informed about receiving outbreak samples.

Although the microbiological quality of water specimens was consistent with the norm, the level of heterotrophic spore-forming bacteria in the ice-cube machine was over the recommended limit. The investigation indicated that the machine had been out of order for a long time before the wedding buffet and had not been used. It is probable that the number of heterotrophic bacteria in the ice cube machine had increased after the water flow in the machine ceased.

During the control visits the health inspectors identified that several staff members at the centre were ill with gastrointestinal symptoms, although they had not been symptomatic while at work. NoV shedding can continue for several weeks in symptomatic and asymptomatic cases $[17,18]$. In hotels, where new cohorts of susceptible guests often change, the staff members that excrete the virus, as well as contaminated surfaces, may prolong the outbreak for several weeks [19].

The extensive environmental investigation indicated the presence of NoV on several surfaces at the centre. The contaminated surfaces in the main building were easily accessible and commonly used. Since NoV infection has a very low infectious dose and noroviruses were detected on door handles and tap handles, contaminated hands could have played a key role in the environmental transmission cycle. Additional cases of gastroenteritis that occurred before and after the wedding reception supported the hypothesis of an environmental transmission of $\mathrm{NoV}$. 
In order to prevent NoV transmission at the centre, we recommended ill staff members stay at home for 2 days after the symptoms had ceased. Careful hand hygiene, always washing with soap and water after toilet visits, and before preparing, serving or eating food decreases the transmission risk [20]. In the kitchen, we drew attention to the recommendation of the Finnish Food Safety Authority that $200 \mathrm{~g}$ frozen samples of all served foods should be stored for 2 weeks at institutional kitchens to enable microbiological investigations after possible outbreaks.

Since several cases of gastrointestinal illness were reported in three guest groups, the accommodation was left unused for a period of 1 week to cut the environmental transmission cycle. During this period, the accommodation was thoroughly cleansed and disinfected. Control specimens for $\mathrm{NoV}$ analyses were taken before the accommodation was returned to use. However, NoV was still isolated in several sites in a hotel room that had been severely contaminated with vomit. The premises were cleansed with detergents and the surfaces disinfected with hypochlorite solution according to THL guidelines [20]. We recommend that: contaminated materials should be treated with water and ordinary detergents and disinfected with $1000 \mathrm{ppm}$ hypochlorite or by steam cleaning; materials with vomit or faecal stains can be disinfected with $5000 \mathrm{ppm}$ hypochlorite, with disposable cleaning cloths used. To avoid droplet infection, the use of disposable gloves, eye-nose mask and apron are necessary during cleaning. Closing the centre for 1 week was recommended. After thorough cleansing and disinfection and 1 week's quarantine, no new cases with symptoms typical for NoV infection were identified at the centre.

The sequence analysis of isolates from two patients and three environmental specimens indicated the same genotype in all specimens. The NoV GII.4 Sydney variant was identified. In March 2012, a new variant of GII.4, designated Sydney, was reported in Australia. Since then, increased activity of this variant has been observed worldwide [21-23]. The NoV GII. 4 Sydney variant was identified for the first time in Finland during this outbreak. It is possible that one of the wedding guests from abroad had imported the new strain to the centre. However, since symptoms typical for NoV infection were also reported in other guests prior to the wedding reception, it is possible that the centre had been contaminated prior to the wedding event. NoV may remain infectious for over
2 weeks on environmental surfaces and in water for over 2 months [24-27].

Noroviruses belonging to GII.4 have been the predominant strain worldwide for over a decade [28]. In 2002, 2004, 2006 and 2010 the number of outbreaks caused by NoV increased markedly [29]. Increased $\mathrm{NoV}$ activity was associated with the emergence of new variants of GII.4 associated with the multiple outbreaks in the USA and Europe: the Farmington Hills variant in 2001-2002, the Hunter virus at the end of 2004, the GII.4-2006a/2006b viruses in 2006, and New Orleans virus in 2010 [30-33]. In 2012, an increased activity of NoV was observed in Australia, New Zealand, France, and Scotland, which may indicate a new epidemic wave caused by the new variant [21].

\section{ACKNOWLEDGEMENTS}

We thank Ülle Kärk and Matti Naukkarinen from Pirteva for performing the sampling at the centre; Mrs Alena Kaijalainen and Svetlana Kaijalainen for skilful technical assistance; and Yvan Hutin for valuable comments and suggestions regarding the manuscript.

\section{DECLARATION OF INTEREST}

None.

\section{REFERENCES}

1. Patel MM, et al. Noroviruses: a comprehensive review. Journal of Clinical Virology 2009; 44: 1-8.

2. Morillo SG, Timenetsky MDCST. Norovirus: an overview. Revista da Associação Médica Brasileira 2011; 57: 453-458.

3. Matthews JE, et al. The epidemiology of published norovirus outbreaks: a review of risk factors associated with attack rate and genogroup. Epidemiology and Infection 2012; 140: 1161-1172.

4. Hall AJ. Noroviruses: the perfect human pathogens? Journal of Infectious Diseases 2012; 205: 1622-1624.

5. Karst SM. Pathogenesis of noroviruses, emerging RNA viruses. Viruses 2010; 2: 748-781.

6. Teunis PFM, et al. Norwalk Virus: How Infectious is it? Journal of Medical Virology 2008; 80: 1468-1476.

7. Koopmans M, Duizer E. Foodborne viruses: an emerging problem. International Journal of Food Microbiology 2004; 90: 23-41.

8. Evans MR, et al. An outbreak of viral gastroenteritis following environmental contamination at a concert hall. Epidemiology and Infection 2002; 129: 355-360. 
9. Kimura $\mathbf{H}$, et al. A norovirus outbreak associated with environmental contamination at a hotel. Epidemiology and Infection 2011; 139: 317-325.

10. Isakbaeva ET, et al. Norovirus transmission on cruise ship. Emerging Infectious Diseases 2005; 11: 154-158.

11. Evira. Microbiological hazards in food, Eviran julkaisuja 1/2010.

12. Maunula L, Von Bonsdorff C-H. Norovirus genotypes causing gastroenteritis outbreaks in Finland 19982002. Journal of Clinical Virology 2005; 34: 186-194.

13. Murray PR, et al. Manual of Clinical Microbiology. Washington, DC: ASM Press, 1995.

14. Loisy F, et al. Real-time RT-PCR for norovirus screening in shellfish. Journal of Virological Methods 2005; 123: $1-7$.

15. Rönnqvist $\mathbf{M}$, et al. Swabs as a tool for monitoring the presence of norovirus on environmental surfaces in the food industry. Journal of Food Protection 2013; 76: 1421-1428.

16. Vinjé J, Hamidjaja RA, Sobsey MD. Development and application of a capsid VP1 (region D) based reverse transcription PCR assay for genotyping of genogroup I and II noroviruses. Journal of Virological Methods 2004; 116: 109-117.

17. Tu ET-V, et al. Norovirus excretion in an aged-care setting. Journal of Clinical Virology 2008; 46: 21192121.

18. Kirkwood CD, Streitberg R. Calicivirus shedding in children after recovery from diarrhoeal disease. Journal of Clinical Virology 2008; 43: 346-348.

19. Kuusi M, et al. A prolonged outbreak of Norwalk-like calicivirus (NLV) gastroenteritis in a rehabilitation centre due to environmental contamination. Epidemiology and Infection 2002; 129: 133-138.

20. Kuusi M, Kanerva M, Lyytikäinen O. Guidelines for prevention and control for norovirus infections, 2007.

21. Van Beek J, et al. Indications for worldwide increased norovirus activity associated with emergence of a new variant of genotype II.4, late 2012. Eurosurveillance 2013; 18: 8-9.

22. Bennett $\mathbf{S}$, et al. Increased norovirus activity in Scotland in 2012 is associated with the emergence of a new norovirus GII.4 variant. Eurosurveillance 2013; 18: 2011-2012.

23. Centres for Disease Control and Prevention. Emergence of new Norovirus strain GII.4 Sydney - United States, 2012. Morbidity and Mortality Weekly Report 2013; 62: 55.

24. Lopman B, et al. Environmental transmission of norovirus gastroenteritis. Current Opinion in Virology 2012; 2: $96-102$.

25. Cheesbrough JS, Barkess-Jones L, Brown DW. Possible prolonged environmental survival of small round structured viruses. Journal of Hospital Infection 1997; 35: 325-326.

26. Seitz SR, et al. Norovirus infectivity in humans and persistence in water. Applied and Environmental Microbiology 2011; 77: 6884-6888.

27. Marshall JA, Bruggink LD. The dynamics of norovirus outbreak epidemics: recent insights. International Journal of Environmental Research and Public Health 2011; 8: 1141-1149.

28. White PA, Eden J, Hansman GS. Molecular epidemiology of noroviruses and sapoviruses and their role in Australian outbreaks of acute gastroenteritis. Microbiology Australia 2012; 33: 70-74.

29. Siebenga JJ, et al. Norovirus illness is a global problem: emergence and spread of norovirus GII.4 variants, 2001-2007. Journal of Infectious Diseases 2009; 200: 802-812.

30. Tu ET-V, et al. Epidemics of gastroenteritis during 2006 were associated with the spread of norovirus GII.4 variants 2006a and 2006b. Clinical Infectious Diseases 2008; 46: 413-420.

31. Verhoef L, et al. Emergence of new norovirus variants on spring cruise ships and prediction of winter epidemics. Emerging Infectious Diseases 2008; 14: 238-243.

32. Bull RA, et al. Emergence of a New Norovirus Genotype II.4 Variant Associated with Global Outbreaks of Gastroenteritis. Journal of Clinical Microbiology 2006; 44: $327-333$.

33. Centres for Disease Control and Prevention. Surveillance for foodborne disease outbreaks - United States, 20092010. Morbidity and Mortality Weekly Report 2013; 62: $41-47$. 